\title{
Retail
}

\section{The UK retail hierarchy: Beyond the shopping centre pipeline}

Received (in revised form): 2 October 2006

\section{Andrew Goodwin}

is a partner at Donaldsons; independent property consultants in the UK and Europe. Andrew joined Donaldsons in 2002 having worked in retail development for 18 years having experience in the out of town food and non food sectors and has been working exclusively on city centre regeneration schemes for the last six years advising on all facets of the development process. His clients are direct occupier investors as well as developers.

\section{Abstract}

Developers have committed to building a high level of new shopping floor space, which comes on stream in the next three years but where is this space and how will it affect the retail hierarchy of those centres, which do and do not have new schemes proposed.

\section{Keywords:}

shopping centre floor space, development pipeline, hierarchy

Journal of Retail and Leisure Property (2007) 6, 79-83. doi:10.1057/palgrave.rlp.5100041

\section{INTRODUCTION}

From the comments made of the estimated $5,000,000 \mathrm{~m}^{2}$ of new shopping centre floor space which forms the basis of the 'pipeline' proposed by developers, taken together with the Retail Forecast and the decline in retail growth rates, one could be forgiven for thinking that vast malls are due to open, with row upon row of unlet shops.

It is not unheard of, it happened in 1989 when the economy was in reverse after a high number of shopping centre openings between 1987 and 1989. The current economic climate, and more importantly the form and location of the latest shopping centres suggest a very different position. ${ }^{1}$

Firstly, there is not $5,000,000 \mathrm{~m}^{2}$ of floor space actually being built or committed to. In fact, the pipeline has consistently projected between $4,000,000$ and $5,000,000 \mathrm{~m}^{2}$ over the last 20 years but this year will only see four significant schemes opened, which include Land Securities' Princess Hay in Exeter, British Land's St Stephens in Hull, Lend Lease's Golden Square in Warrington and Modus Properties' Grand Arcade in 


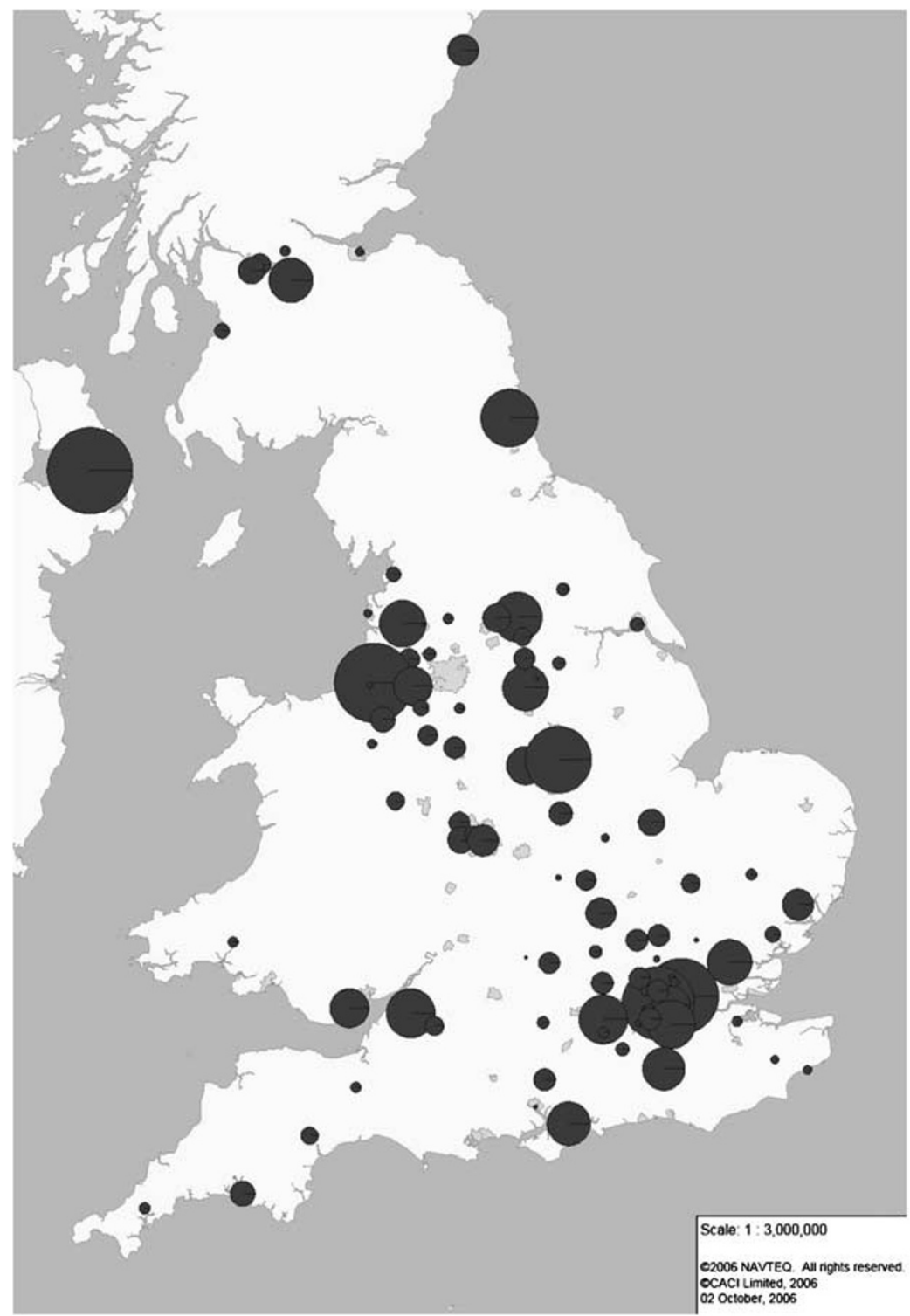

Figure I: UK shopping centre pipeline by area weighting 2006-2012 (reproduced with permission of $C A C l$ and NAVTEQ)

Wigan. Each of these is well conceived and designed to provide the unit sizes and arrangement retailers are looking for. In 2008, proposed centre openings follow a similar story; the eight largest schemes make up 75 per cent of the proposed $1,000,000 \mathrm{~m}^{2}$ floor space and five of these, Land Securities/Hammerson's Broadmead Bristol, Multi Development's Belfast, Grosvenor's Cambridge and Liverpool One, and Westfield's White City in London could be considered regional centres. They are well dispersed strategically important schemes with regeneration benefits. Importantly, perhaps with the exception of the White City development, they are all located in traditional city centres.

Beyond these projected openings, developers have only committed to two further shopping centres, although it is clear that their intention 


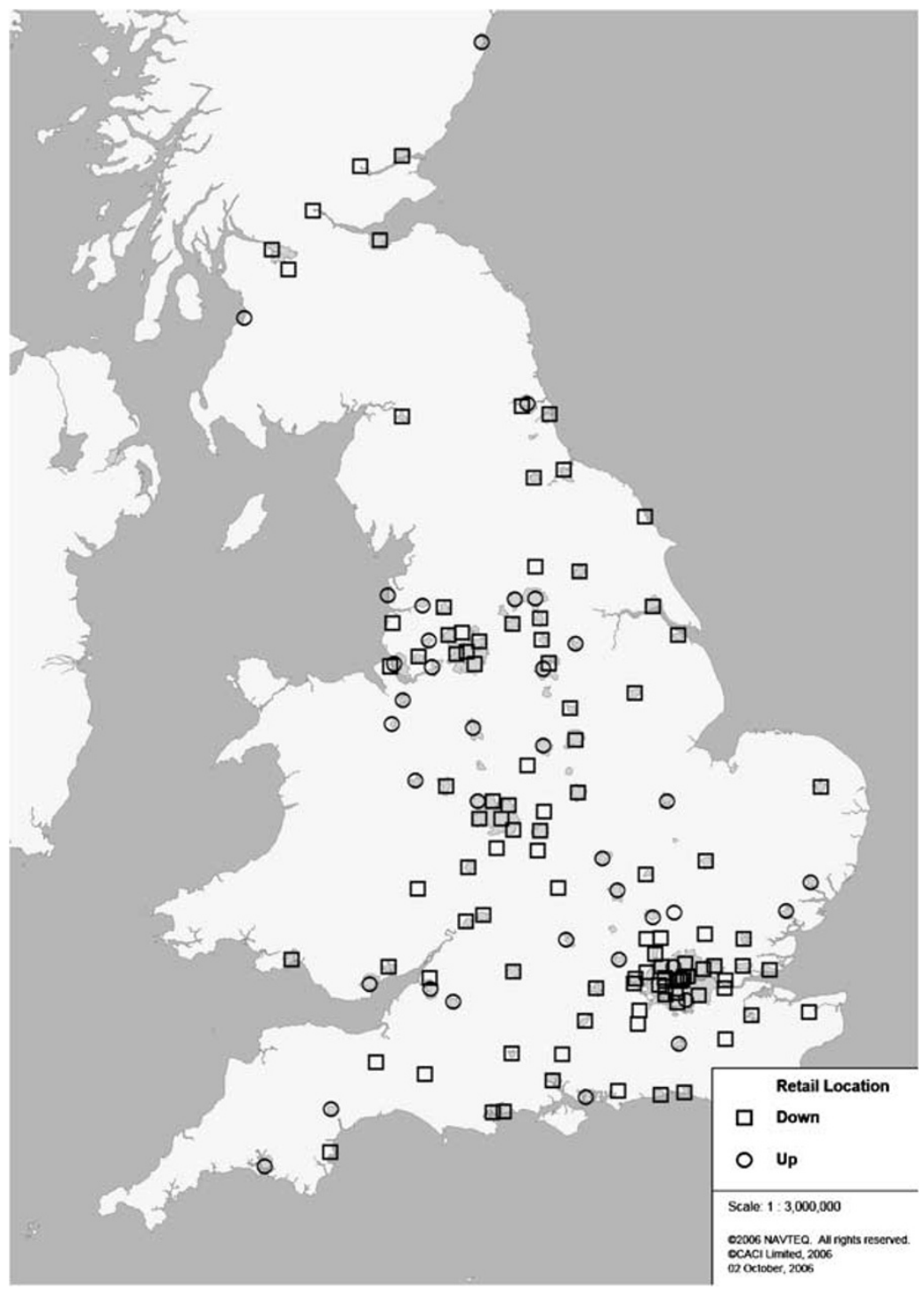

Figure 2: Projected movements in retail hierarchy in top 150 towns (reproduced with permission of $\mathrm{CACl}$ and NAVTEQ)

remains to overcome the planning and site assembly hurdle at the earliest possible time, it is only at that point that pre-lettings and the recently projected outward moving yields will dictate whether they can proceed. If current conditions remain unchanged, there is likely to be a further healthy opening programme in 2009 of around $500,000 \mathrm{~m}^{2}$.

This close scrutiny at the point of committing to a scheme will undoubtedly lead to some developers needing more time to obtain the commitment from retailers that they require for their pre-letting thresholds, or more efficient site assembly techniques (such as relocations rather than extinguishments) and of course a large part of the viability will depend upon built cost inflation, most prevalent in the south east, but relevant throughout the UK, not being too damaging.

Of the projected $578,000 \mathrm{~m}^{2}$ potentially able to commit for opening in 2009 , it could be expected that 25 per cent will require more time 
to overcome either technical or viability issues which arise in the lead in.

It is possible to project the location and size of futute openings within the pipeline for the period 2006-2012 and a pattern emerges showing the concentration of centres within the North West of England, London and the East and West Midlands (Figure 1).

\section{RETAIL HIERARCHY}

Given such a large amount of new floor space projected to open, it is important to forecast the impact of new centres on those existing shopping destinations within affected catchments. The large efficient centres within the projected pipeline will affect the retail hierarchy and it can be predicted now which cities or regions will benefit or suffer as a consequence (Figure 2).

Donaldsons have undertaken a study of this projected hierarchy by estimating the increased customer draw for each town or city with its completed centre. Liverpool, for example, which is likely to move up five places back into the top 10 of UK retail centres, is unlikely to significantly extend its catchment primarily as a result of the new centres opening and protecting their shopping catchment in Warrington, Chester, Birkenhead and Wigan.

The greater strength of Liverpool's retail offer will increase its penetration by up to 15 per cent in much of its existing primary and secondary catchment area. That is, it is expected that 15 per cent more people will use Liverpool as their primary shopping destination within these areas. With the nearby new centres also increasing their core penetration, those centres missing this phase of development are likely to see a significant loss of custom. The problem is exacerbated if the region is overlaid by a deprivation index, which indicates that the good are getting better through investment and the deprived areas continue to lack investment.

The East Midlands will see a slightly different trend, with schemes in the three main centres of Derby, Leicester and Nottingham. Leicester, with Hammerson's innovative High Cross Quarter, will not significantly raise the city up the national hierarchy but it will increase the market share of Leicester within its primary and secondary catchment, without which it will surely fall dramatically. Again the combination of these three cities becoming increasingly strong is likely to reduce trade in the smaller centres within the catchment, which will have fallen down the national hierarchy rankings.

This situation contrasts with the South West where Exeter will open within a catchment which otherwise would be largely unaffected by the pipeline (West of Bristol). While having a limited increase in the national rankings, Exeter will become a strong dominant centre within the catchment and is expected to trade strongly as the dominant sub-regional centre.

Another expected trend is for the out of centre shopping centres to fall down the hierarchy, a result of the prevailing planning policies, which clearly seek to encourage city centre development. The effect on some of 
these centres catchment population once the new city centre schemes are open could result in a 15 per cent drop in their catchment population.

The pipeline for London is dominated by Hammerson's schemes in Brent Cross and Kingston, Westfield's schemes at White City and Stratford and the Minerva/Lend Lease scheme in Croydon. Again, if the London map is overlaid by a deprivation index it is conspicuous that the areas of high deprivation such as Tower Hamlets and Lea Valley are least well served. The implication is that without new retail-led mixed use schemes, these areas will continue to decline further by offering less retail, leisure and services choice. It is the complexity of developing in London, which holds back new investment, but initiatives such as that at Elephant \& Castle seek to address this.

\section{SUMMARY}

It appears that proposals exist for each of the of the main UK regions and subject to overcoming technical, market and viability issues beyond the 2009 openings there will be a substantial reorganisation of the UK retail hierarchy. The characteristics of these changes can be summarised as follows:

- Only a limited amount of the overall UK shopping centre pipeline is committed to construction at this time but those openings in 2007, 2008 and 2009, which are expected to total 1.75 million $\mathrm{m}^{2}$ are expected to be successful.

- The North West sees a significant amount of new floor space with a number of towns surrounding Liverpool's proposals defending their catchment with new schemes.

- Liverpool is likely to increase its penetration by 15 per cent from their primary and secondary catchment at the expense of smaller centres.

- The East Midlands will continue the trend for dominant cities rather than spreading the investment in the smaller centres, which are likely to further lose out.

- The London region is dominated by large schemes at the expense of lower ranked centres and areas of high deprivation.

- The planning policies are likely to result in existing out of centre schemes falling down the retail rankings.

A large part of the future pipeline remains uncertain, however, it is clear that where there is a region with a significant number of schemes these with draw trade from smaller centres, which have not received investment and this trend is currently most prevalent in the North West of England, the East Midlands and London.

\section{Reference}

1. Banham, R. (2006). The UK shopping centre development market. Journal of Retail and Leisure Property. 5(3) 239-246. 